\title{
TEMA ABIERTO
}

\section{El peso del trabajo esclavo en el ciclo productivo de la campaña de Buenos Aires tardocolonial. Una estimación a partir de un estudio de caso: Los Portugueses (1808-1812)*}

\section{Emilio Fabián Harari}

Afiliado institucionalmente al Centro de Estudios e Investigaciones en Ciencias Sociales-CEICS (Argentina). Correo electrónico: harari@live.com.ar. El autor es doctor en Historia de la Universidad de Buenos Aires (Argentina). Entre sus publicaciones recientes tenemos: "La población miliciana ante la justicia militar en Buenos Aires (1810-1823). Una comparación entre la ciudad y la campaña", Revista de Indias Vol. 75 No. 264 (2015). Entre sus temas de interés están Revolución burguesa y Formación de los Estados nacionales.

JuAN GABRIEL Flores

Afiliado institucionalmente al Instituto de Investigaciones en Humanidades y Ciencias Sociales-IDIHCS (Argentina). Correo electrónico: juan.g.flores2014@gmail.com. El autor es licenciado en Historia de la Universidad de Buenos Aires (Argentina). Entre sus publicaciones recientes tenemos: "¿utilidad o producción de Valor? Trabajo y relaciones de producción en una estancia colonial rioplatense a partir del caso de Los Portugueses", Revista Temas Americanistas, No. 34 (2015). Entre sus temas de interés está Historia Agraria.

Recibido: 30 de octubre de 2016

Aprobado: 27 de marzo de 2017

Modificado: 10 de abril de 2017

Artículo de investigación científica

DOI: http://dx.doi.org/10.15648/hc.32.2018.2

Este artículo forma parte del proyecto: "Las relaciones sociales de producción en el Buenos Aires tardocolonial y revolucionario" financiación propia.

Esta publicación está bajo una licencia Creative Commons Reconocimiento-NoComercial 4.0 
El peso del trabajo esclavo en el ciclo productivo de la campaña de Buenos Aires tardocolonial. Una estimación a partir de un estudio de caso: Los Portugueses (1808-1812)

\title{
Resumen
}

El presente artículo tiene por objetivo una caracterización social del fenómeno de la esclavitud para el espacio colonial del Río de la Plata, explicando su forma de inserción dentro del universo de las relaciones sociales de producción. Para ello, observaremos su importancia en el mundo del trabajo, allí donde los esclavos producían mercancías agrarias. El artículo propone un estudio de caso de una estancia colonial: Los Portugueses, ubicada en Chascomús. Allí observaremos la incidencia del trabajo esclavo en el proceso de trabajo y creación de valor, en comparación con el peonaje rioplatense, tomando la totalidad de los días-hombre en la estancia y distinguiendo el "tiempo de trabajo" y el "tiempo de producción".

Palabras clave: producción, valor, trabajo esclavo, peones.

The weight of slave labor in the productive cycle of the late-colonial Buenos Aires campaign. An estimate based on a case study: Los Portugueses (1808-1812)

\begin{abstract}
This article aims at a social characterization of the phenomenon of slavery for the colonial period of the Río de la Plata, explaining its way of insertion into the universe of social relations of production. For this, we will observe its importance in the world of work, where the slaves produced agrarian goods. The article proposes a case study of a colonial period: Los Portugueses, located in Chascomús. There we will observe the incidence of slave labor in the work process and creation of value, in comparison with River Plate peonage, taking the totality of man-days in the period and distinguishing between "working time" and "production time". .
\end{abstract}

Keywords: production, value, slave labor, workmen.

O peso do trabalho escravo no ciclo produtivo da campanha de Buenos Aires tardocolonial. Uma estimativa baseada em um estudo de caso: Os Portugueses (1808-1812)

\section{Resumo}

O presente artigo tem por objectivo uma caracterização social do fenómeno da escra- 
vatura para o espaço colonial do Rio da Prata, explicando sua forma de inserção dentro do universo das relações sociais de produção. Para isso, observaremos sua importância no mundo do trabalho, ali onde os escravos produziam mercadorias agrárias. O artigo propõe um estudo de caso de uma estadia colonial: Os Portugueses, localizada em Chascomús. Ali observaremos a incidência do trabalho escravo no processo de trabalho e criação de valor, em comparação com o peonaje rioplatense, tomando a totalidade dos dias-homem na estadia e distinguindo o "tempo de trabalho" e o "tempo de produção".

Palavras-chave: produção, valor, trabalho escravo, peones.

Le poids du travail esclave dans la période productive de la campagne de Buenos Aires dans le tard de la période coloniale. Une considération à partir d'une étude de cas: Les Portugais (1808-1812)

\section{Resumé}

Cet article a pour objectif une caractérisation sociale du phénomène de l'esclavage pour l'espace colonial de Río de la Plata, en expliquant sa forme d'insertion dans l'univers des relations sociales de production. Pour ce faire, nous regarderons son importance dans le monde du travail, celui où les esclaves produisaient des marchandises agricoles. L'article propose une étude de cas d'un groupe colonial : les Portugais, situé à Chascomús. Nous pourrons aussi observer l'incidence du travail esclave dans le processus de travail et création du courage, par rapport aux ouvriers rioplatenses, en prenant la totalité des jours-homme dans la ferme et en distinguant le «temps du travail » et le «temps de production ».

Mots clés: production, courage, travail esclave, ouvriers.

\section{INTRODUCCIÓN}

Entre fines del siglo XVIII y principios del siglo XIX, la ciudad de Buenos Aires asistió a una reciente pero rápida expansión económica, al calor de la apertura de su puerto (Reglamento del Libre Comercio de 1778) y de su establecimiento como nueva capital del Virreinato del Río de la Plata. La ciudad-puerto hasta entonces relegada a puerto de contrabando, comenzaba a dar pasos más fuertes como eje fundamental en el territorio americano. El crecimiento de su comercio y finanzas, el desarrollo demográfico 
y la expansión de su binterland fueron aspectos que caracterizaron dicha expansión ${ }^{1}$.

En lo que refiere al binterland, pudieron cotejarse numerosas unidades productivas en la campaña de Buenos Aires: desde pequeñas y medianas producciones agrícolas hasta grandes estancias agropecuarias ${ }^{2}$. La predominancia de unas u otras unidades dio lugar a una relativa diferenciación regional, donde las grandes estancias del sur de la campaña, de reciente ocupación y de paulatina expansión, comenzaban a tomar forma preeminentemente ganadera. En efecto, las estancias comenzaron a vivir un mayor desarrollo técnico y a consolidar sus stocks ganaderos, así como requerían de un mayor control del territorio en expansión. Entre estas estancias, podemos ubicar la que analizaremos aquí, ubicada en Chascomús, pago de la campaña de Buenos Aires. El destino de su producción podía ser de carne para el Abasto de Buenos Aires como cueros para el mercado internacional, entre otros derivados de la producción ganadera ${ }^{3}$.

Como en el resto de América Latina, en dichas estancias, el trabajo forzado convivió con el trabajo asalariado (también llamado "libre"). En algunas regiones, como la que aquí tratamos, ese compartir se constataba en las propias unidades productivas. No faltaron, por lo tanto, quienes veían en ellas la marca del atraso y de la dominación de una clase precapitalista ${ }^{4}$.

1 Tulio Halperin Donghi, Revolución y guerra. Formación de una elite dirigente en la Argentina criolla (Buenos Aires: Siglo XXI, 1972), 41.

2 Juan Carlos Garavaglia, Pastores y Labradores de Buenos Aires. Una historia agraria de la campaña bonaerense, 1700-1830 (Buenos Aires: Ediciones de la Flor, 1999); Carlos Mayo, Estancia y sociedad en La Pampa, 1740-1820 (Buenos Aires: Editorial Biblos, 2004).

3 Juan Carlos Garavaglia, Pastores y labradores de Buenos Aires; Juan Carlos Garavaglia. "Tres estancias del sur bonaerense en un período de 'transición' (1790-1834)”, en Problemas de Historia agraria. Nuevos debates y perspectivas de investigación, eds. María Bjerg y Andrea Reguera (Tandil: Instituto de Estudios Histórico-Sociales-Facultad de Ciencias Humanas-Universidad Nacional del Centro de la Provincia de Buenos Aires, 1995).

4 Eduardo Azcuy Ameghino, El latifundio y la gran propiedad colonial rioplatense (Buenos Aires: García Cambeiro, 1995); Eduardo Azcuy Ameghino, La otra Historia. Economía, Estado y Sociedad en el Río de la Plata Colonial (Buenos Aires: Imago Mundi, 2002); Sergio Bagú, Estructura social de la colonia (Buenos Aires: Editorial El Ateneo, 1952); Jacinto Oddone, La burguesía terrateniente argentina (Buenos Aires: Ediciones Libera, 1975); Leonardo Paso, Rivadavia y la línea de Mayo (Buenos Aires: Editorial Fundamentos, 1960); Milcíades Peña, Antes de Mayo (Buenos Aires: Ediciones Fichas, 1970); Rodolfo Puigróss, Los caudillos de la Revolución de Mayo (Buenos Aires: Editorial Contrapunto, 1972 [1942]). 
En las últimas décadas, trabajos de una óptica liberal concibieron a esas unidades como "empresas" y a sus dueños, como "empresarios", considerados capitalistas que llevaban "racionalmente" su explotación".

Las preocupaciones por comprender el contenido de esas explotaciones "mixtas" produjeron cierto corpus de conocimiento acumulado. Sin embargo, la metodología utilizada para cuantificar la importancia de dichas relaciones ( $\mathrm{y}$, por lo tanto, las consecuencias que se deducen) obligan a una revisión de las formas de medir el peso de las relaciones sociales. Eso es lo que trataremos de hacer en este artículo. Para ello, examinaremos cómo se desenvuelven ambas relaciones (esclavistas y asalariadas) en una estancia del Buenos Aires correspondiente a los períodos tardocolonial y revolucionario. De ese modo, avanzaremos en torno a una caracterización más certera de las relaciones esclavistas y del lugar que estas ocupaban históricamente, desde un aspecto cuantitativo. Ante todo, nos es preciso definir el objeto de estudio ante el cual nos encontramos, para de ese modo, observar lo que nos compete con herramientas conceptuales precisas.

\section{EsClAVITUD: CONCEPTO HISTÓRICO Y TEÓRICO}

La esclavitud fue un fenómeno muy difundido en todo el continente americano. Normalmente, la mayor parte de los estudios sobre el tema han

5 Osvaldo Barsky y Julio Djenderedjian, Historia del capitalismo agrario pampeano. La expansión ganadera hasta 1895 (Buenos Aires: Universidad de Belgrano/siglo XXI, 2003); Jonathan Brown, "A nineteenth Century Argentine cattle empire", Agricultural History Vol. 1 No. 52 (1978), 160-178; Roberto Salvatore y Jonathan Brown, "Trade and proletarianization in Late Colonial Banda Oriental: Evidence from the Estancia de Las Vacas, 1791-1805”, Hispanic American Historical Review Vol. 3 No. 67 (1987), 431-459; Julio Djenderedjian, “¿Peones o esclavos? Producción rural, tasa de ganancia y alternativas de utilización de la mano de obra en dos grandes estancias del sur del Litoral a fines de la Colonia", Terceras Jornadas de Historia Económica (2003), 1831-1850. La producción de esta escuela influyó incluso a autores con otros orígenes teóricos: Juan Carlos Garavaglia, "Tres estancias del sur bonaerense". Juan Carlos Garavaglia, Pastores y labradores de Buenos Aires; Jorge Gelman, "Sobre esclavos, peones, gauchos y campesinos: el trabajo y los trabajadores en una estancia colonial rioplatense", en El mundo rural rioplatense a fines de la época colonial: estudios sobre producción y mano de obra, eds. Juan Carlos Garavaglia y Jorge Gelman (Buenos Aires: Fundación Simón Rodríguez, 1989), 43-83; Jorge Gelman, Campesinos y estancieros. Una región del Río de la Plata a fines de la época colonial (Buenos Aires: Ediciones Libros del Riel, 1998); Tulio Halperin Donghi, Una estancia en la campaña de Buenos Aires, 1753-1809, en Haciendas, latifundios y plantaciones en América Latina, ed. Enrique Florescano (México: siglo XXI, 1975), 447-463. 
diferenciado entre la esclavitud de plantaciones (sur de Estados Unidos, Caribe y Centroamérica, algunas regiones de Brasil), la esclavitud en áreas urbanas y en áreas de estancias o haciendas, como Buenos Aires. En efecto, para 1800, los esclavos se hacían presentes en la campaña y ciudad-puerto de forma relativamente significativa. La historiografía argentina, de ese modo, ha observado en la esclavitud rioplatense un actor de importancia, atendiendo a varios aspectos: el comercio, el derecho y su estatus legal, su participación activa en los ejércitos, sus diferentes labores, su vida cotidiana, entre otros.

Una primera comprensión del fenómeno en la historiografía argentina no ha escapado a dos modelos teóricos medianamente perceptibles, que definen a la esclavitud como un fenómeno reducido a la relación de propiedad del amo sobre el esclavo. Uno de ellos es la concepción funcionalista que considera a la esclavitud como una relación puramente mercantil entre dos agentes comerciales (cazador-plantador), omitiendo la relación de producción misma (esclavista-esclavo) ${ }^{6}$. Sin ir más lejos, en los clásicos y valiosos estudios sobre trata negrera y la mercantilización del esclavo, no se reflexiona sobre la esclavitud como relación de producción ${ }^{7}$. Por el contrario, la esclavitud es observada como el bien mercantil apropiado y negociado en una transacción: se trata del esclavo-objeto.

Sin embargo, la adquisición del esclavo no es equivalente a la adquisición de un objeto cualquiera. En primera instancia, porque el esclavo es un sujeto preso de la coacción: la captura, el traslado, la vigilancia, el castigo, son duras formas de impedir que este realice sus condiciones de vida por fuera de la relación esclavista misma. En segundo lugar, porque su condición es la de trabajador: se espera que rinda un determinado tiempo de trabajo, comprometiendo para ello, toda o parte de su energía humana.

6 Estas críticas ya fueron realizadas en alguna bibliografía especializada sobre la esclavitud. Destacamos en particular a Cláude Meillassoux, Antropología de la esclavitud: el vientre de hierro y dinero (México: Siglo XXI, 1990), 11. El antropólogo francés vierte precisamente parte de las críticas que aquí retomamos y reivindicamos.

7 Por ejemplo, Elena Studer, La trata de negros en el Río de la Plata durante el siglo XVIII (Buenos Aires: FFyL, UBA, 1958); Diego Luis Molinari, La trata de negros. Datos para su estudio en el Río de la Plata (Buenos Aires: Universidad de Buenos Aires, 1944). 
Por otra parte, el precio del esclavo puede incorporar diferentes variables: el esclavista paga por él un tiempo de producción, captura y traslado (es decir, el tiempo de producción para reproducir la mercancía "esclavo"), adelantando una porción del excedente que este podría producir. La diferencia entre el costo y lo que la mercancía desprende (o se le obliga a desprender) constituye el elemento central de la explotación. Es decir, en la relación mercantil misma existe ya el contenido de la explotación, es decir, una relación social de producción entre hombres.

Por otra parte, la escuela liberal se ha concentrado en la esclavitud como un hecho jurídico, en tanto la cosificación del esclavo y su resultante apropiación es sancionada legalmente. Varios estudios se realizaron al respecto: aquellos que observan en los esclavos las discapacidades y disminuciones jurídicas, como aquellos que intentan observar sus "derechos" en tanto "personas", y por lo tanto, concluían un supuesto carácter "benevolente" del Derecho Castellano-Indiano ${ }^{8}$. No hay dudas de que la sanción normativa cumplía una función determinante en este tipo de relación, dado que

8 Para el primer caso, pueden citarse trabajos que han apostado a observar las continuidades de la disminución jurídica en el período posrevolucionario, sin observar transformaciones de las relaciones sociales en términos materiales y postulando la misma concepción liberal de la esclavitud. Ver en: Liliana Crespi, "Esclavos, libres y libertos del Río de la Plata. Un lento acceso a la ciudadanía", en La ruta del esclavo en el Río de la Plata. Aportes para el diálogo intercultural, ed. Marisa Pineau (Tres de febrero: EDUNTREF, 2011); Orestes Carlos Cansanello, "Sujeciones personales y puniciones en Buenos Aires durante el siglo XIX", Revista de Historia del Derecho No. 35 (2007), 47-81. Para los del segundo caso, varios trabajos han apuntado los "derechos" de los esclavos como personas y su posibilidad de defenderlos ante la justicia. Ver por ejemplo: Alejandro Fernández Plastino "Justicia Colonial y esclavos en Buenos Aires virreinal", Anais do X Congreso Internacional de Alada-Universidad Cándido Méndez, Río de Janeiro (2002); Abelardo Levaggi, "La condición jurídica del esclavo en la época hispana”, Revista de Historia del Derecho No. 1 (1973), 83-175; Manuel Lucena Salmoral, Leyes para esclavos. El ordenamiento jurídico sobre la condición, tratamiento, defensa y represión de los eslavos en las colonias de la América española (Madrid: Fundación MAPFRE, 2005); Eugenio Petit Muñoz; Edmundo Narancio y José Traibel Nelcis, La condición jurídica, económica y política de los negros durante el coloniaje en la Banda Oriental (Montevideo: Publicaciones oficiales de la Facultad de Derecho y Ciencias Sociales, 1947). Dichos trabajos se corresponden con una idea general sobre el carácter del derecho y la esclavitud en América (Debate Tannembaun). Alejandro De la Fuente, "La esclavitud, la ley y la reclamación de derechos en Cuba: repensando el debate Tannembaun", Debate y perspectivas. Cuadernos de Historia y Ciencias Sociales 4 (2004), 37-68; Alejandro De la Fuente, "Su único derecho: los esclavos y la ley", Debate y perspectivas. Cuadernos de Historia y Ciencias Sociales 4 (2004): 7-22. Un buen resumen de todo este debate puede observarse en Lucas Rebagliatti, “ ¿Una esclavitud benigna? La historiografía sobre la naturaleza de la esclavitud rioplatense”, Andes, Vol. 25, No. 2 (2014), http://www.scielo.org.ar/scielo.php?script=sci_arttext\&pid $=$ S1668-80902014000200005. 
dicha población debía ser mantenida en una situación que variaba desde la disminución jurídica hasta la cosificación. En efecto, el Derecho confería así autoridad a los amos para obligar a los esclavos a permanecer y trabajar para ellos? ${ }^{9}$. Sin embargo, el Derecho es tan solo un cuerpo normativo que tiene real vigencia en la medida que existan ciertos mecanismos sociales que generan y reproducen relaciones esclavistas. Además, aún en los casos de exacerbada cosificación del esclavo en términos jurídicos, es imposible trazar una identidad entre este y una herramienta. Si el esclavo fuera una herramienta, el esclavista no podría acumular un excedente (diferencia entre la subsistencia y el producto de trabajo) y no haría falta vigilarlo asiduamente.

Finalmente, la reciente historiografía argentina ha realizado numerosos aportes en torno al problema de la esclavitud en el Río de la Plata en el temprano siglo XIX. Se ha postulado la capacidad de los esclavos de condicionar la relación de dominación existente (por un relativo acceso a la justicia y su capacidad de adaptación al entorno social), su implementación de estrategias de acumulación y de "vías de escape" de su situación, su acceso a bienes varios, entre otros elementos ${ }^{10}$. Los estudios, de ese modo, han permitido complejizar su realidad material y apuntar la diversidad de tipos de esclavos en Buenos Aires. Así, sabemos hoy que para 1778, la

9 Cláude Meillassoux, Antropología de la esclavitud; Geoffrey De Ste Croix, La lucha de clases en el mundo griego antiguo: De la época arcaica a la conquista árabe (Barcelona: Editorial Crítica, 1988).

10 Hay varios trabajos que podrían citarse en estos puntos: Marta Goldberg y Silvia Mallo, "Trabajo y vida cotidiana de los africanos de Buenos Aires (1750-1850)", Vida cotidiana de los negros en Hispanoamérica, eds. Marta Golberg (Madrid: Ignacio Larramendi-MAPFRE Tavera, 2005), 1-39; Lyman Johnson, "La manumisión de esclavos en el Buenos Aires colonial: un análisis ampliado", Desarrollo Económico, No. 17 (1978), 637-646; Lyman Johnson, Los talleres de la Revolución. La Buenos Aires plebeya y el mundo del Atlántico, 1776-1810 (Buenos Aires: Prometeo Libros, 2013); Silvia Mallo, "Población afroamericana: del peculio al matrimonio y la propiedad", Actas del XII Congreso de Arqueología, La Plata (1999); Silvia Mallo, "La población africana en el Río de la Plata. Delito, adaptación y negociación”, en Vida cotidiana de los negros en Hispanoamérica, eds. Marta Goldberg (Madrid: Ignacio Larramendi-MAPFRE, 2005), 1-12; Carlos Mayo, Estancia y sociedad en La Pampa; Miguel Ángel Rosal, Africanos y afrodescendientes en el Río de la Plata. Siglos XVIII-XIX (Buenos Aires: Dunken, 2009); Mario Rufer, Historias negadas: esclavitud, violencia y relaciones de poder en Córdoba de fines del siglo XVIII (Córdoba: Ferreyra Editor, 2005); Eduardo Saguier, "La naturaleza estipendiaria de la esclavitud urbana colonial. El caso de Buenos Aires en el siglo XVIII", Revista Paraguaya de Sociología, No. 74 (1989), 45-54. 
población afroamericana (esclavos y libertos) de Buenos Aires conformaba un $29 \%$ de la población, sobre un total de 24 mil habitantes. En la campaña, cubrían un $13 \%$ sobre un aproximado de 13 mil habitantes ${ }^{11}$. Para 1813-1815, el porcentaje de esclavos cubre un 7,8\% sobre 42 mil habitantes ${ }^{12}$.

Entre estos esclavos de Buenos Aires, conocemos realidades disímiles: esclavos rurales sin mayor acceso ni usufructo de bienes, esclavos de naturaleza estipendaria que cobran un jornal y tributan al amo, esclavos que conforman familia y acceden a una pequeña parcela. Del mismo modo, existieron esclavos de naturaleza africana coactivamente trasladados al suelo rioplatense, como esclavos naturales de Buenos Aires, hijos de madre esclava. En lo que hace a las tareas productivas, hubo esclavos que se desempeñaban en las más diversas tareas rurales, así como esclavos que se desempeñan en tareas domésticas (por ejemplo, en un casco de estancia). Algunos esclavos incluso tomaron el rol de capataces y mayordomos de estancias.

Como vemos, toda una realidad variopinta se esconde tras el concepto histórico de "esclavo", exponiendo que este es mucho más que un objeto mercantil y un hecho jurídico. Sin embargo, ante la diversidad, corresponde comprender la condición común. Ello nos lleva en definitiva a preguntarnos qué entendemos por esclavo en tanto concepto teórico y científico, y si ese concepto permite englobar toda esa realidad que parece tan diversa.

En efecto, aquí postulamos que aquello que aparece como determinante de este tipo de relaciones es la coacción política utilizada para obtener plustrabajo, es decir, para lograr realizar el hecho de la explotación. De este modo, la esclavitud es una relación en la que una clase social obtie-

11 Goldberg, Marta, "La población negra y mulata de la ciudad de Buenos Aires 1810-1840", Desarrollo Económico, No. 16, (1976), 79-91.

12 Grupo de Investigación en Historia Rural Rioplatense, "La sociedad rural bonaerense a principios del siglo XIX. Un análisis a partir de las categorías ocupacionales", en En busca de un tiempo perdido. La economía de Buenos Aires en el país de la abundancia, 1750-1864, eds. Raúl Fradkin y Juan Carlos Garavaglia (Buenos Aires: Prometeo Libros, 2004). 
ne un excedente por la vía de la expropiación sistemática de productores directos para la extracción patrimonial y coactiva de un máximo físico posible de energía laboral, en términos vitalicios, por encima del trabajo necesario para su subsistencia inmediata ${ }^{13}$.

¿Qué significa esto? En primer lugar, la expropiación sistemática implica la separación violenta entre el productor directo y sus condiciones de reproducción: la fuerza misma convierte al campesino africano en cautivo, la cual es utilizada hasta agotar la reserva disponible de las sociedades agrarias que ofician de fuentes de esclavos. Esta caracterización también es atendible para los esclavos naturales de estos suelos -hijos de madres esclavas-, en tanto constituyen sujetos que no pueden disponer libremente de bienes materiales en tanto propietarios para subsistir, sin concesión del amo. En segundo lugar, el esclavo es patrimonializado, es decir, se ostenta la propiedad privada -más o menos definida, según sea el caso más preciso- de los hombres, lo cual es una particularidad de estas relaciones.

La pregunta entonces emerge: ¿y cómo cuaja aquí la realidad de los esclavos que accedían a una porción de tierra para su propia subsistencia, como aquellos que accedían a un jornal, como aquellos que podían acumular y "comprar" su "libertad jurídica"? En primer lugar, en ninguno de los casos, estamos hablando de esclavos que no rinden plustrabajo a sus propietarios, ya sea por hacerlo por la vía tributaria o por trabajar directamente para ellos. En segundo lugar, pese a usufructuar riquezas, en última instancia, el esclavo dispone de ellas solo bajo arbitrio del amo y no como propietario libre. Por el contrario, la fuerza del Estado (sea por sus sanciones legales, o por la mediación de la Justicia) debía mantener al esclavo en su estado, salvo que el amo dispusiera de lo contrario. Así, podemos citar algunos de los pocos litigios judiciales sobre el asunto, como el del esclavo José, propiedad de Juan Ximénez de Paz, hacendado del Magdalena, quien fuera beneficiado con una serie de crías de caballos para que invirtiese el producto en su alimento y vestuario "con el disfrute de mayor comodidad”. Al haber alegado José un derecho de propiedad, Ximénez de Paz argumentaría que ello "sería constituirle en clase de propietario, dueño y

13 Fabián Harari, "El barro de la historia" en: Ciryl Lionel Robert James, Los jacobinos negros (Buenos Aires: Ediciones RyR, 2013), 16. 
Señor de lo mismo mío, cuando no tenía capacidad, ni tenía libertad”. Juan José Castelli, su abogado, señalaba al respecto:

"Estos actos en los amos no dan propiedad en el esclavo, porque el contrato no es entre capaces de ambas partes, y por eso es que llevan implícita la reserva del dominio pleno del Señor; así como cuando este mejora el trato de la vida del siervo con vestuario, habitación y muebles no es visto hacerlo dueño de todo, ni se priva al amo de quitarle cuando quiera lo que le permitió usar"14.

Como se ve, la ley y la costumbre estipulaban lo contrario a lo solicitado por el negro José. Los bienes y el resultado de la producción, en última instancia, seguían sujetos a la propiedad del amo. Así, estamos ante una realidad material que también se presenta en otros casos históricos. $\mathrm{Al}$ respecto, en sus estudios de sociedades esclavistas africanas, Meillasoux ha distinguido entre "esclavos de fatiga" y "esclavos parceleros", es decir, entre los que cumplen enteramente su jornada laboral a disposición del amo, y los que disfrutan de la concesión de tierras para dedicar una porción de las jornadas a su propia subsistencia ${ }^{15}$. Así, tras la noción de "promoción social", subyace la continuidad de la relación esclavista. La compra de la libertad, por otra parte, no representaba un camino al que llegara la mayor parte de los esclavos, y en última instancia, colocaba a los libertos en una condición de disminución jurídica que expresaba cierto grado de sujeción material.

Otro elemento presente en la definición que hemos presentado es el de la extracción coactiva de una energía laboral. El esclavista adquiere por vías mercantiles un cuerpo que contiene un mínimo de energía, la cual es extraída por la fuerza. A diferencia de lo que acontece bajo el capitalismo, el esclavista no compra fuerza de trabajo por un tiempo determinado sino el cuerpo que contiene tanto la energía como la disposición a trabajar. Para extraerlos, el esclavista debe apelar a la coacción y derrotar así la resisten-

14 Citado en Eduardo Saguier, "Retribución estipendiaria de la esclavitud urbana colonial”, en Genealogía de la Tragedia Argentina, Tomo I, Sección B, 6, http://www.er-saguier.org/obras/gta/Tomo-I/ Seccion-B/Cap-6/0-COM-07.pdf.

15 Claude Meillassoux, Antropología de la esclavitud, 132-133 
cia humana. En efecto, el problema principal para el esclavista no es tanto maximizar el uso de la fuerza laboral sino conseguirla. Es decir, el esclavista adquiere al esclavo como un elemento objetivo de producción, pero debe usarlo como uno subjetivo.

Respecto al máximo físico, el tiempo de trabajo no encuentra límite sino en el agotamiento físico. De hecho, la relación es vitalicia porque el esclavista debe ser capaz de extraer hasta la última gota de energía vital del esclavo. En efecto, el esclavista pagó un precio por el esclavo y debe amortizarlo. Y no termina de ser plenamente propietario de eso que compró hasta que su propiedad no dé todo de sí.

Habiendo abordado estos problemas teóricos y conceptuales, en lo que sigue estudiaremos la incidencia del trabajo esclavo en términos productivos, en el marco de una estancia puntual de la campaña de Buenos Aires.

\section{Trabajo y relaciones esclavistas en una estancia colonial}

¿Cuál es el peso de cada relación social dentro de una estancia? ¿Qué lugar ha tomado el esclavo históricamente en las estancias rioplatenses? Algunas de estas preguntas serán contestadas a partir del abordaje de un estudio de caso, basado en las contabilidades de la estancia Los Portugueses, una gran estancia de Buenos Aires, ubicada en Chascomús. Consideraremos la relación establecida entre la mano de obra esclava y asalariada (o denominada muchas veces "libre") en el proceso de trabajo de las mercancías agrarias, desde una perspectiva que priorice el problema de la creación de valor y la estacionalidad del trabajo agrario. En este sentido, intentaremos comparar la incidencia de las diferentes relaciones sociales englobadas en la estancia en términos de creación de valor.

Por ello, volveremos a observar algunos estudios que han avanzado sobre la comparación entre la mano de obra "libre" y el trabajo esclavo a fin de presentar algunas objeciones y plantear una perspectiva metodológica alternativa. Como veremos, no encontramos allí a las clases explotadas como productoras de valor, lo cual es un elemento fundamental para cotejar el peso de cada relación. Acto seguido, nos introduciremos de lleno 
en los números de la estancia Los Portugueses entre 1808 y 1812, cuando las contabilidades se muestran completas y fiables en el registro de la mano de obra.

\section{LA HiSTORIOGRAFÍA Y EL MÉTOdo DE TRABajo PARA MEDIR LAS RELA- CIONES SOCIALES}

Muchos trabajos han relevado de alguna manera la comparación entre el peso de los peones y los esclavos en el ámbito productivo de la campaña de Buenos Aires. Tales son los casos de Samuel Amaral, Jorge Gelman, Juan Carlos Garavaglia, Carlos Mayo y Julio Djenderedjian ${ }^{16}$. En líneas generales, la discusión ha planteado la alternativa entre dos modalidades del trabajo rural: las tareas estacionarias y las tareas permanentes de la estancia. Dichos problemas se conjugaban con un debate sobre la caracterización de la llamada mano de obra "libre" (peones y agregados), asunto que aquí dejaremos de lado. Basta solo decir que algunos estudios han asociado al peón de estancia al campesino (Gelman, Garavaglia), un semiproletario con actitud preindustrial (Salvatore-Brown), una población con acceso a medios de reproducción (Mayo) o agentes que responden a la demanda externa (Amaral). Otros estudios han señalado que el peonaje temporario puede esconder una impronta reciprocitaria, como parte de una herencia andina (Garavaglia) ${ }^{17}$.

Samuel Amaral fue el primer historiador en poner cifras a la estacionalidad del trabajo agrario colonial. En efecto, su metodología consistió en calcular los días-hombre para los peones de la estancia de López Osornio (abuelo de Juan Manuel de Rosas), a partir del estudio de las contabilidades halladas en las sucesorias. Allí, logró contribuir con una contabilización de las jornadas laborales estimadas por mes entre febrero de 1787 y enero

16 También pueden destacarse: Karl Monsma, "Esclavos y trabajadores libres en las estancias del siglo XIX. Un estudio comparativo de Río Grande Do Sul y Buenos Aires", en De la Región a la Nación, relaciones de escala para una historia comparada Brasil-Argentina (S. XIX y XX), eds. Andrea Reguera y Marluza Marques Harres (Tandil: Buenos Aires, 2012), 83-120.

17 AAVV, "Polémica: gauchos, campesinos y fuerza de trabajo rioplatense colonial", Anuario IHES No. 2 (1987), 25-70; Juan Carlos Garavaglia, Pastores y labradores; Roberto Salvatore y Jonathan Brown, "Trade and proletarianization in Late Colonial Banda Oriental". 
de 1792, cuando las fuentes se presentaban en forma más específica ${ }^{18}$. En efecto, Amaral establecía la diferencia entre dos períodos de tiempo: cuando los peones se contrataban en grandes cantidades en la estancia y cuando no lo hacían. Es decir, la estancia se manejaba optando por demandar mano de obra en los dos meses de recogida y marca del ganado a comienzos del otoño, dos meses de siembra a fin del otoño y comienzos del invierno, dos meses de recogida y marca del ganado en primavera, y dos meses de cosecha a fin de primavera y comienzo del verano. Entre los períodos, había fracciones de tiempo sin tareas urgentes, es decir, se recurría a tareas permanentes. Las estacionarias determinaban así la demanda de mano de obra: mientras las permanentes de la estancia eran ejercidas por los esclavos y las tareas estacionarias prioritariamente por los peones libres. Para ello, se avanzó con operaciones aritméticas, de entre las cuales, suponía el costo de amortización de los esclavos y ataba su productividad a los ingresos por las atahonas, cueros y equinos, como si el esclavo no hubiera tenido incidencia alguna en el ciclo de la cría del vacuno. Por otra parte, el individualismo metodológico de su concepción liberal lo hacían suponer tácitamente que estas complejas operaciones podían ser realizadas por los mismos estancieros, lo que le valió algunas críticas, dado que al menos la mayor parte de estos organizadores de la producción, según la muestra de Carlos Mayo, eran ágrafos ${ }^{19}$.

Jorge Gelman ha trabajado sobre la estacionalidad poniendo especial énfasis en la oferta de mano de obra como elemento determinante ${ }^{20}$. En efecto, Gelman señalaba la contraposición entre la economía familiar campesina y la producción de la estancia como alternativas de tiempo de trabajo. A partir del estudio de la estancia Las Vacas, ubicada en la Banda Oriental, él observaba que en enero se producían las deserciones de los peones -usual motivo de queja de los hacendados rioplatenses-, lo que explicó por su carácter campesino. Para el autor, estos peones regresaban a sus siegas en sus unidades familiares, aunque podrían también buscar un salario más alto. A partir del mes de marzo, comenzarían las entradas más marcadas Di Tella, 1989).

19 Carlos Mayo, Estancia y sociedad en La Pampa, 137.

20 Jorge Gelman, Campesinos y estancieros, 194-195. 
de la estancia Las Vacas hasta fin de año, volviéndose la entrada de mano de obra un fenómeno regular durante todo el año. Gelman postulaba que en Las Vacas, solo 11 de 22 esclavos se ocupaban en el ciclo productivo y una parte de ellos ejercían como capataces. A esos capataces y baqueanos, se le sumaban los otros esclavos también dedicados a las tareas mínimas del ciclo pecuario, así como las reparaciones, la matanza de plagas, etc. No existiría entonces allí una decisión de ahorrar en peones utilizando esclavos, incluso en las épocas de siega -cuando la mano de obra libre se pagaba con salarios más altos-, sino una decisión de poseer un plantel permanente con funciones directivas en el ciclo productivo. Durante todo el año, la estancia empleaba de manera regular a un número elevado de peones.

Entonces, ¿por qué utilizar esclavos como plantel permanente? Gelman señala que el principal motivo residía en el bajo precio comparado con la media internacional de los esclavos, siempre y cuando los esclavos trabajasen al menos diez años. A partir de haber configurado ese núcleo de trabajadores permanentes, la estancia pasaba a reclutar peones durante todo el año, siguiendo las fluctuaciones de los ciclos productivos, en términos anuales (la estacionalidad) como interanuales (la variabilidad de los ciclos productivos año tras año por causas diversas). Dentro de la última variable, podrían hallarse múltiples factores que justifiquen la negación a comprarse más esclavos que los permanentes: guerras, sequías, etc. Asimismo, Gelman sostiene la posibilidad de contratar más mano de obra libre sin mayores dificultades y por precios razonables, exceptuando los meses de siega. Estos peones, por otra parte, no necesariamente se destinaban a tareas estacionarias sino que se ligaban también a tareas permanentes ${ }^{21}$.

Carlos Mayo también señalaría a la oferta de mano de obra "libre" como el factor determinante de la entrada y salida de peones de estancias. Indicaba que "el ocio y el vagabundaje" eran la forma en que se presentaban diferentes alternativas de vida para los peones como el abigeato y el acceso directo al consumo y a diferentes bienes ofrecidos en los circuitos de mer-

21 Jorge Gelman, “Sobre esclavos, peones”, 58. 
cancías de la frontera ${ }^{22}$. De esa manera, Mayo apeló a numerosas fuentes y testimonios de la época que revelarían los motivos de los contemporáneos para emplear mano de obra esclava. Allí suponía que, como en términos comparativos con otras regiones, el costo de la mano de obra libre era alto -y suponía una sangría alta de metálico-, los estancieros preferían esclavos. Mayo agregaba que los contemporáneos preferían la productividad del esclavo, su confiabilidad y estabilidad en contraposición a los peones. Sin embargo, la combinación de trabajo "libre" y esclavo se debía a los mismos motivos que ya había señalado Gelman: la estancia debía cubrir la "demanda sobrante de mano de obra derivada no solo de las actividades temporarias más o menos estacionales, sino también de las permanentes"23. Mayo agregaba, basándose en fuentes cualitativas, que los esclavos podían cumplir varias funciones de todo el ciclo agropecuario: no solo la matanza de perros, faenas cotidianas o para rodeo, sino también las tareas de la yerra o la siega.

Djenderedjian ha tomado el caso comparativo de dos estancias entrerrianas para la primera década del siglo XIX, con características completamente antagónicas: mientras una se valía completamente de peones, la otra solo apelaba a la mano de obra esclava. Al respecto Djenderedjian apuntaba que ambas formas de explotación eran igual de rentables. Con el mismo marco teórico que Samuel Amaral, el autor apelaba a complejas operaciones en las que estimaba la utilidad, la tasa de ganancia o la productividad del trabajo ${ }^{24}$.

En definitiva, el grueso de los estudios se ha concentrado en definir los probables motivos de incorporación de uno u otro tipo de relación social en la organización del proceso de trabajo. Sin embargo, muy pocos han procurado medir concretamente el del trabajo esclavo y el peso del trabajo asalariado, lo cual nos permitirá razonar acerca de la predominancia de

22 Carlos Mayo, Estancia y sociedad, 151-152.

23 Carlos Mayo, Estancia y sociedad, 138.

2824 Julio Djenderedjian, “¿Peones o esclavos?”, 1831-1850. Véase también: Julio Djenderedjian, “Optimizando recursos escasos en un área de frontera: La opción por la mano de obra esclava en grandes estancias entrerrianas de tiempos coloniales", Quinto Sol, Vol. 15, No. 2 (2011): 1-27, http://www. scielo.org.ar/scielo.php?script $=$ sci_arttext\&pid $=\$ 1851-28792011000200001 \& \operatorname{lng}=\mathrm{es} \& \mathrm{nrm}=$ iso 
uno sobre otro. A continuación, veremos algunos cálculos que al respecto ha realizado Juan Carlos Garavaglia sobre la estancia Los Portugueses. Dada la importancia de estas cuentas para el curso de nuestra investigación, le dedicaremos todo el apartado siguiente.

\section{Trabajo “libre” y trabajo esclavo en los portugueses Según la HISTORIOGRAFÍA}

En líneas generales, los trabajos de la renovación historiográfica procuraron demostrar la existencia de un campesinado en la campaña porteña, basándose en el modelo de Chayanov ${ }^{25}$. Por ende, los análisis de los movimientos de la peonada intentaban en el fondo aportar un conocimiento en este sentido. Al respecto, Garavaglia se sumaba a observar la rotación en la estancia tomando Los Portugueses como estudio de caso, de la que más adelante brindaremos algunos detalles ${ }^{26}$. Garavaglia calculaba que, entre septiembre de 1807 y 1812, se contabilizaron alrededor de 28.869 mil jornadas, en 109 entradas. Eso implicaría una media de 275 días de trabajo y una media por entrada de 139 días, con un muy bajo porcentaje de "fallas", las cuales se concentraban en los peones de mayor antigüedad. A ello Garavaglia agregaba las entradas y salidas para el mismo período. La regularidad observada lo llevaba a postular que los peones entraban a trabajar en enero y febrero y tendían a salir entre octubre y noviembre cuando se iban a trabajar a la siega a otras estancias o a sus propios sembrados, según si en la estancia la cosecha fuera abundante.

Es decir, para Garavaglia había dos elementos en juego: la demanda de la estancia para las tareas agrarias - para la siega en enero y febrero- y en las tareas pecuarias -febrero y, en menor medida, junio-, combinada con la opción del peón por permanecer allí -si había suficiente trigo- o conchabarse en otra estancia, chacra o dedicarse a su propia producción familiar, si la tuviere. Estaríamos ante una estacionalidad como marco global de la

25 Alexander Chayanov, La organización de la unidad económica campesina (Buenos Aires: Ediciones Nueva Visión, 1985 [1925]); Alexander Chayanov, "Sobre la teoría de los sistemas económicos no capitalistas". Cuadernos Políticos No. 5 (1975): 15-31; Juan Carlos Garavaglia, Pastores y labradores; Jorge Gelman, Campesinos y estancieros, 199.

26 Juan Carlos Garavaglia, "Tres estancias del sur". 
demanda, que implicaría un escenario donde los peones elegían su lugar de trabajo.

En este caso, Garavaglia concluía que el hecho de que las estancias se vieran en dificultades de contratar mano de obra en verano, respondería a los movimientos de las unidades domésticas en un contexto de puja entre la demanda global de la campaña y el acceso de diversos tipos de producciones. Por ello, debían pagar los hacendados una mensualidad de 8 reales, cuando en el resto del año pagaban 6. Del mismo modo, Garavaglia demostraba con cuentas que la cantidad de mano de obra que demandaban las grandes unidades productivas para la cosecha no podía siquiera ser cubierta por la escasa población de la campaña ${ }^{27}$. Por ende, esto aumentaba la competencia por la mano de obra.

Respecto a las jornadas laborales, algunas cuentas generales de Garavaglia estipulaban la utilización de 12 esclavos, 4 capataces (2 de ellos esclavos) y la contratación de 16 trabajadores en un período ideal de 365 días (es decir, 32 trabajadores todos los días del año), aunque aclaraba que sería más realista señalar que eran 4 capataces, 12 esclavos y 22 peones, nueve meses al año ${ }^{28}$. Acto seguido, Garavaglia estimaría que tomando alrededor de 12 mil jornadas laborales anuales, un $63 \%$ correspondería a jornaleros y capataces libres y un $37 \%$ a esclavos. Sin embargo, ¿es esta cuenta demostrativa del verdadero peso de las relaciones laborales? Nuestra suposición es que, por lo contrario, son cuentas algo superficiales. En principio, porque como el lector imaginará, una estimación del total sobre jornadas anuales (calculadas según promedio sobre las más de 28 mil jornadas para los cinco años) pueden sobreestimar el peso de las relaciones esclavistas, en tanto, no logran percibir en qué períodos de tiempo, su peso fue mayor y en cuáles menor en términos comparativos. Si la producción de la estancia es al mismo tiempo, creación de valor, y esta se concentra sobre todo en períodos de gran contratación de los jornaleros, lo que correspondería demostrar es en qué períodos del ciclo productivo, el trabajo esclavo supera o se equipara con el de los peones.

27 Juan Carlos Garavaglia, Pastores y labradores, 195.

28 Juan Carlos Garavaglia, “Tres estancias del sur”, 106. 
Del mismo modo, aunque Garavaglia comprende el problema de la estacionalidad como determinante de la cantidad de peones y esclavos que laboran en la estancia, para explicarlo recurre únicamente a la contabilización de entradas y salidas, sin revisar la cuenta más precisa: la de los días-hombre por mes o por un período determinado de tiempo. Aunque explica el movimiento general de algunos peones, Garavaglia no da cuenta del constante recambio de la peonada en la estancia. Por poner un ejemplo mínimo: cuando en 1808, entraron 16 peones en febrero, solo 3 de ellos salieron entre octubre y noviembre, al fin de la yerra. El resto lo hizo a lo largo del año. Tampoco -nuevamente- expresa con esta cuenta la incidencia del peso del trabajo de los peones y de los esclavos en el ciclo productivo por cada rubro - ganadero o agrícola- y estación.

\section{Tiempo de TRABAJO Y TIEMPo de PRODUCCIÓN}

El principal problema de estas visiones historiográficas es que no han planteado la posibilidad de la producción de valor como un eje del ciclo productivo de la estancia. Su análisis de la producción en la estancia carece de la perspectiva de la explotación, en tanto la producción de mercancías implica la cristalización de valor ${ }^{29}$. En razón de este problema, el relevo de la incidencia del trabajo esclavo y el trabajo asalariado posee una limitación: pensando únicamente en qué tareas encarga a cada uno el ciclo de producción, no han evaluado qué tareas crean valor y cuáles no. Ello implica un asunto fundamental en los ciclos agrarios, dado que allí prevalece un factor fundamental como el de la estacionalidad.

En segundo lugar, la evaluación de las cifras, sobre todo, en torno a la estimación de las entradas y salidas de los peones de la estancia, puede pasar por alto la incidencia de cada uno en la producción de la estancia. Al concentrarse en analizar el ciclo del productor directo dentro y fuera de la estancia, los autores de la renovación historiográfica han perdido de vista su relevancia como productores de valor, en la medida que tan solo han

29 Karl Marx, El Capital, Tomo I (México: Fondo de Cultura Económica, 2000); Juan Gabriel Flores, "¿Utilidad o producción de valor? Trabajo y relaciones de producción en una estancia colonial rioplatense a partir del caso de Los Portugueses (1802-1809)", Revista Temas Americanistas, No34 (2015): $99-123$ 
sumado días-hombre en la estancia, sin relevar que los mismos no indican necesariamente tiempo de trabajo para la producción de valor. Por ejemplo, debemos considerar que parte del ciclo productivo involucraba tareas menores: la matanza de plagas, la reparación de un corral ó la vigilancia de una sementera.

En definitiva, para relevar el ciclo productivo de la estancia tendremos en cuenta algunas precisiones metodológicas. Rescataremos un concepto relegado pero no por ello menos fundamental del ciclo agrario, la división que Marx establecía entre tiempo de trabajo y tiempo de producción:

"El propio proceso de producción puede provocar interrupciones del proceso laboral y por ende del tiempo de trabajo, intervalos en los cuales se abandona el objeto de trabajo a la acción de procesos físicos, sin agregado ulterior de trabajo humano. En este caso el proceso de producción, y por tanto la función de los medios de producción, continúa aunque esté interrumpido el proceso laboral y en consecuencia la función de los medios de producción como medios de trabajo. Así ocurre, por ejemplo, con el grano que se ha sembrado, con el vino que fermenta en la bodega, con el material de trabajo de muchas manufacturas, como por ejemplo, el de las curtiembres que queda sujeto a procesos químicos. En estos casos, el tiempo de producción es siempre mayor que el tiempo de trabajo. La diferencia entre ambos consiste en un excedente del tiempo de producción sobre el tiempo de trabajo. Este excedente siempre se basa en que el capital productivo se encuentra de manera latente en la esfera de la producción, sin actuar en el proceso de producción mismo, o bien, en que actúa en el proceso de producción sin encontrarse en el proceso laboral" 30 .

Es decir, mientras el ciclo de producción es la totalidad del proceso de producción de la mercancía final, las tareas rurales contemplan fases de contratación de mano de obra que incorporan mayor valor. Mientras producir un novillo apto para el abasto de Buenos Aires podía tomar años

30 Karl Marx, El Capital, Tomo II, Vol. 4 (Buenos Aires: Siglo XXI, 2009), 144-145. 
enteros como parte del ciclo productivo, algunas tareas fundamentales de la mano de obra en la producción de esta mercancía se concentraba en períodos más acotados.

\section{LA FUENTE}

Los Portugueses era un complejo estanciero ubicado en Chascomús (campaña sur de reciente ocupación), cuya propiedad pertenecía a la familia de Antonio Rivero de los Santos, al menos entre los años 1784 y 1815. Se trataba de una estancia opulenta, de más de 40 mil hectáreas. Para 1805, año de su última tasación, poseía un stock de 13 mil vacunos. Es decir, operaba en una escala notoriamente superior al de otros productores. Fue fundada en los años 60 por el propio Rivero, luego vendida transitoriamente ${ }^{31}$ y vuelta adquirir en 1784, durante un proceso de liquidación de bienes del que Rivero ejercía como albacea ${ }^{32}$. Una vez adquirida la estancia y luego de arrendar en 1784 el diezmo de cuatropea (impuesto eclesiástico usualmente arrendado por grandes estancieros con el afán de acrecentar su stock ganadero), la estancia se volvió uno de los puntales de lanza de la producción pecuaria de la campaña de Buenos Aires ${ }^{33}$. Para 1805, Los Portugueses se dividía en tres partes específicas con sus respectivos capataces y presentaba varios rodeos, con ganado de diverso pelaje y de buen grado de refinamiento.

Para tener una noción acabada de su importancia productiva debemos considerar que para 1800, su producción estaba orientada principalmente a la venta de ganado vacuno en pie para el Abasto de Buenos Aires, como en otras ocasiones hemos expresado ${ }^{34}$. El Abasto constituía un mercado al que fluían las cabezas de ganado de diversos productores oferentes. Estaba regulado por el Cabildo, en conflicto con los intereses de comercializadores y abastecedores que conectaban a los productores ganaderos con los mercados de la ciudad. La fijación de los precios en dichos mercados escapaba entonces al poder de los hacendados ${ }^{35}$.

31 AGN, Protocolos Notariales, R 6, 1771.

32 AGN, Sucesiones No. 8143.

33 AGN, Sala IX, 13-4-7.

34 Juan Gabriel Flores, “¿Utilidad o producción de valor?”, 122

35 Juan Gabriel Flores, "Hacendados, Cabildo y "corraleros". El acceso de los hacendados al abasto de carne a partir del estudio de dos estancias de la campaña sur de Buenos Aires (1785-1809)", Revista Sociedades Precapitalistas, Vol. 4, No1 (2014). Al respecto, como hemos concluido en estos estudios, los hacendados no dominaban los circuitos mercantiles del ganado ni del cuero. Por el contrario, se encontraban subordinados a una clase de comerciantes que expresaban intereses sociales opuestos. 
Por otra parte, la testamentaria de la estancia Los Portugueses constituye una fuente muy rica. Allí la administración que la regía a la muerte de su propietario -Antonio Rivero de los Santos- ha legado una contabilidad detallada para los años de 1802-1809, así como dos inventarios muy completos: uno para 1790 -cuando Rivero fue intimado por una deuda contraída con una compañía de Río de Janeiro y debió tasar todos sus bienes- y otro para 1805 -tras la muerte de Rivero, cuando un administrador debió regir los destinos de la testamentaria-. Del mismo modo, posee una serie de cuadernos que permiten contabilizar el ingreso y egreso de la mano de obra asalariada entre 1808 y 1812, dando por lo tanto, información muy fiable sobre sus jornadas laborales ${ }^{36}$. Al respecto, la estancia contrataba un gran caudal de mano de obra, sobre lo que tenemos detalles muy precisos como veremos más adelante. Estos datos serán fundamentales para contabilizar las jornadas laborales de los peones. Del mismo modo, el inventario de 1805 nos adentrará en el plantel de esclavos, sobre los que podremos calcular también un aproximado de jornadas laborales. Pese a la disparidad temporal de las fuentes, veremos que es posible aproximar un número de plantel de esclavos para 1808-1812, sin problemas. Ajustaremos entonces los datos a este período temporal porque es en este momento cuando las fuentes sobre peones son más precisas.

Como señalamos, nuestra operación distinguirá entre el tiempo de producción y el tiempo de trabajo. La metodología consistirá en una comparación cuantitativa entre los dos rubros de la mano de obra, atendiendo a la cantidad de días-hombre que podemos estimar. Es preciso señalar, sin embargo, que todo cálculo de este tipo para una sociedad agraria de este período necesariamente resultará aproximativo. Sin embargo, nos puede brindar una tendencia clara en el peso de las relaciones sociales.

\section{LOS ESCLAVOS DE RIVERO}

Como señalamos, los inventarios que hemos mencionado nos introducen al plantel de esclavos. Tomaremos aquel que más se aproxima a los años de 1808 a 1812, cuando tenemos un registro de peones muy preciso. A continuación, vemos el plantel para 1805:

36 AGN, Sucesiones, $N^{\circ} 7776$ y 7777. 
Tabla 1. Esclavos en los inventarios de 1805

\begin{tabular}{|l|c|}
\hline \multicolumn{1}{|c|}{ Esclavo } & Pesos \\
\hline Por el capataz llamado Juan de 58 años & 400 \\
\hline Por su mujer llamada Paula de edad de 30 años & 425 \\
\hline Por el hijo mayor llamado Juan Antonio de 14 años & 300 \\
\hline Por el segundo Laureano de edad de 9 años & 250 \\
\hline Por el tercero llamado Florencio de dos años & 140 \\
\hline Por la cuarta hija llamado Ignacia de edad de 4 años & 200 \\
\hline Por el mulato de 22 años llamado Agustín & 350 \\
\hline Por el negro Domingo de 26 años & 300 \\
\hline Por el negro Bautista de 27 años & 325 \\
\hline Por el negro Antonio lisiado de 26 años & 200 \\
\hline Por el negro Joaquín con tacha de borracho de 50 años & 250 \\
\hline Por el mulato capataz de la Estancia de afuera llamado José de 34 años & 450 \\
\hline Por el negro Evangelista de 27 años & 230 \\
\hline $\begin{array}{l}\text { Por el negro Quintillán cocinero con tachas en la ciudad borracho y huidor } \\
\text { de 34 años }\end{array}$ & 200 \\
\hline Total & 4020 \\
\hline
\end{tabular}

Fuente: AGN, Sucesiones, No. 7776

¿A cuáles esclavos de aquellos expresados en la Tabla 1 nos vamos a circunscribir para evaluar el peso de los esclavos en la producción agropecuaria? Primero, como dijimos, a todo aquel que trabaje en los años comprendidos entre 1808 y 1812. Para eso, debemos tomar solamente a los que para ese entonces se hallaran en edad productiva, considerando el mínimo de 12 años de edad. Es decir, debemos quitar a Florencio y a Ignacia. En cambio, ya para 1808, podremos contabilizar a Laureano que habrá estado en edad productiva. De hecho, si atendemos a las erogaciones en mano de obra de 1812, cuando Laureano ya tendría alrededor de 15 años, Martín Rivero -hijo del difunto Antonio Rivero- le concedió un "freno", elemento necesario para montar el caballo, animal indispensable para toda tarea agropecuaria.

Del mismo modo, descartaremos aquellos que sean considerados "criado doméstico" o "cocinero" -por no verse involucrados en el proceso de 
producción-. Es decir, descartamos al negro Quintillán y a Paula, quien oficiaba de criada en el casco de la estancia.

Debemos considerar además que la testamentaria debía registrar todo tipo de movimiento de esclavos. Si uno era enviado a trabajar en la ciudad o en otro rubro productivo, la testamentaria debía informarlo. Del mismo modo, debía sentarse cuando un esclavo fallecía o era vendido, por tratarse de movimientos que afectaban el total del valor a repartir correspondiente a los bienes de la testamentaria. Así, para 1805, Joaquín era enviado a la ciudad, a trabajar de zapatero. Y allí permanecería hasta el cambio de administración. Finalmente, no tenemos información de fallecimientos ni adquisiciones desde dicha tasación. Por ello, podemos suponer que para 1808-1810, la estancia contaba con nueve esclavos en edad productiva, destinados a tareas agrarias. Para 1810, otros dos esclavos eran enviados a la ciudad, pasando entonces a conformar un plantel de siete esclavos de estancia hasta 1812 .

Por otra parte, si atendemos a la tendencia observada en la Tabla 1, podemos identificar que la estancia comienza a relegar en la familia del capataz Juan un reemplazo de la mano de obra esclava saliente. Se trata de una familia esclava en el seno de la unidad productiva y con acceso a porciones de tierra. No tenemos información de que la familia haya accedido a la libertad, es decir, no hay información de que hayan "acumulado". Asimismo, es menester destacar que dos de los tres capataces de la estancia eran esclavos. Como vimos en el primer apartado, esta era una realidad común en Buenos Aires, pero no anulaba la condición común de la esclavitud. Aunque no tenemos muchos datos de los otros esclavos, es probable que su situación fuera más rudimentaria y estuvieran sometidos a tareas varias sin concesión de bienes en particular. No sabemos el origen de los esclavos (salvo aquellos nacidos en el seno familiar), por lo que no podemos señalar si fueron introducidos o nacidos en suelo americano.

Por otra parte, Joaquín sería un esclavo de naturaleza estipendaria, como aquellos que ha caracterizado Eduardo Saguier. La testamentaria registraría para la misma época un ingreso de dinero entregado por Joaquín, por fuera del plustrabajo aportado por los esclavos en la producción agrícola. 


\section{Mano de obra y trabajo en Los Portugueses (1808-1812)}

Abordemos entonces los ciclos anuales de trabajo en la estancia entre 1808 y 1812, con el objetivo de verificar el peso de las relaciones de peonaje y las esclavistas en el proceso de incorporación de valor. Para ello observaremos ahora los libros de cuentas, que registraban el ingreso y salida de los peones para este período ${ }^{37}$. Si queremos establecer entonces una operación más correcta para evaluar el problema en cuestión, debemos tomar en cuenta algunas variables que den cuenta de la producción de valor en la estancia. Para ello, debemos partir del análisis de la estancia en particular y de sus ciclos productivos anuales, así como prestar atención a la división entre el tiempo de trabajo y el tiempo de producción. Sin embargo, no podemos medir en términos cuantitativos el monto de valor incorporado por cada tarea del ciclo productivo, razón por la cual, nuestra estimación de la importancia de cada rubro de la mano de obra no puede ser sino aproximativa. Aun así, consideramos que con las operaciones aquí desarrolladas, estaremos en condiciones de verificar una estimación particular del peso de cada rubro de la mano de obra.

¿Qué podemos inferir de las fuentes sobre la estancia? En primer lugar, y como adelantamos, la misma se destaca por su producción ganadera, en particular para el Abasto, para la cual produce por un valor de 18.000 pesos para 1802-1809, es decir, un $90 \%$ de la producción de la estancia. La producción agrícola en cambio, no parece encontrarse en la base de la producción de la estancia. Y no debe extrañar demasiado: Liborio Rivero -el hijo de Antonio- tenía permitido amasar un pequeño caudal basado en la venta de trigo producido en la estancia, "fugándolo" de los bienes divisibles, tan solo por administrar las estancias del padre. Es evidente entonces que la producción agrícola no era determinante para la reproducción ampliada de la estancia. En efecto, con ello Los Portugueses repetían las características más comunes de toda estancia del sur de la campaña: la de dedicarse en esencia a la ganadería ${ }^{38}$. La agricultura podía también costear parte de la producción para la subsistencia de la mano de obra. Sin embargo, claramente no estaba especializada en el negocio.

37 Archivo General de la Nación, Sucesiones Nº7777, “Quaderno de Peones” (1807-1810 y 18101811), "Papeletas pagadas a peones" (1810-1812) y "Cuaderno de peones de lo de muleque".

38 Garavaglia, Juan Carlos, “Tres estancias del sur”, 326-328. 
Podemos comenzar el análisis apuntando la importancia de la ganadería no solo como producción de animales sino de valor. El ciclo ganadero parece contener en sus momentos de mayor algidez en términos de contratación de la mano de obra, la mayor concentración de producción de valor. Por ende, debemos observar cuándo se producen estos momentos en los ciclos anuales de la estancia. A partir del siguiente gráfico ${ }^{39}$ podemos acercarnos a una primera aproximación del asunto:

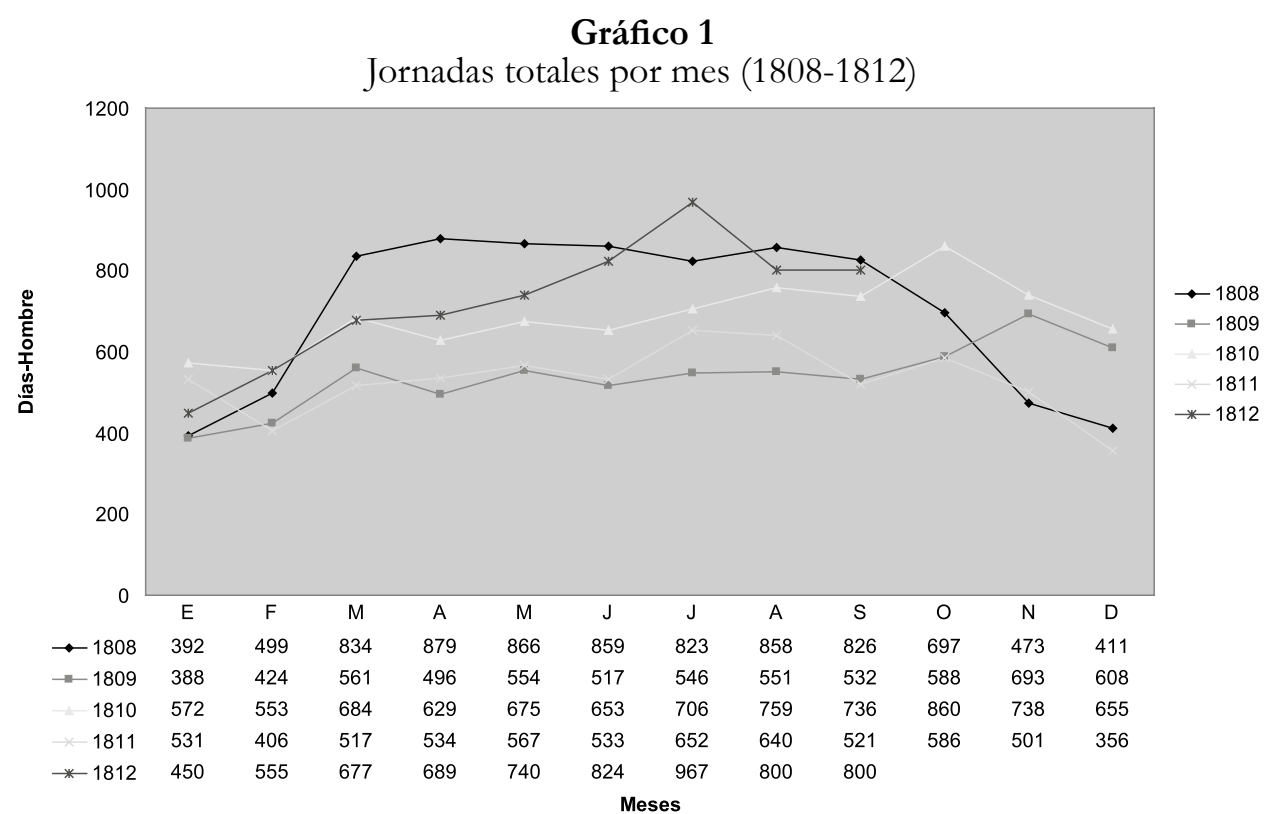

Fuente: Elaboración propia en base al Archivo General de la Nación, Sucesiones Nº7776 y 7777.

39 Con base en AGN, Sucesiones, No. 7776 y 7777. La estimación de jornadas laborales supone la sumatoria de 9 esclavos para $1808-1810$ y 7 para 1810-1812, y todos los peones que, entre ingresos y egresos documentados en los cuadernos mencionados en la referencia No. 36, han estado residiendo en la estancia en esos mismos años. Esos valores se multiplican por los días de trabajo, según los calendarios de 1808-1812. Vale hacer una precisión: las tablas y gráficos en cuestión poseen algunas diferencias respecto de las estimaciones de Juan Carlos Garavaglia, "Tres estancias del sur". En principio, Garavaglia contabiliza alrededor de 28 mil jornadas laborales totales para los trabajadores "libres". Nuestras cuentas, sin embargo, arribaron a una cifra de 24.262 jornadas laborales. Uno de los elementos que Garavaglia no tomó en cuenta es la costumbre del descanso dominical para los peones que ya Carlos Mayo ha probado con fuentes cualitativas. Por ejemplo, recordemos uno de los testimonios de un peón rural: "El domingo como es costumbre en el campo que oye misa la peonada de las estancias, se juntan varios en una pulpería adonde pasan rato, beben un trago y se divierten unos con otros". Ver Carlos Mayo, Estancia y sociedad, 128. Asimismo, para poder contar con mayor exactitud las jornadas laborales y el peso relativo de cada rubro de la mano de obra, decidimos descontar los datos para fines de 1807 (septiembre-diciembre), dado que solo contabiliza aquellos que ingresaron o salieron en dichos meses, sin dar cuenta de la cantidad de peones que ya estaban allí. Por otro lado, Garavaglia cuenta erróneamente doce esclavos para el período. 
En efecto, a raíz del movimiento global de la mano de obra en 1808-1812, podemos observar cómo las tareas ganaderas determinan en términos de días hombre los ciclos productivos. La mayor cantidad de días hombres comienzan a registrarse en marzo manteniéndose con una tendencia constante hasta octubre. Durante esos meses, la estancia registra la mayor cantidad de trabajadores. ¿A qué tareas pueden quedar afectados estos trabajadores rurales? No necesariamente la siembra, dado que no requería demasiada mano de obra. En cambio, podemos suponer un alto ingreso de mano de obra para la doma de potros hasta mayo, las pariciones de mayo a septiembre, las castraciones en invierno, acompañadas de la yerra desde mediados de dicha estación hasta octubre (preferentemente en la primavera). Inferimos que la estancia registraba una marcación de 3.000 y 3.300 vacunos en 1808 y 1809 respectivamente ${ }^{40}$. Asimismo, cada 12 hombres, se podían marcar 200 terneros en un plazo indefinido de tiempo ${ }^{41}$. La estacionalidad queda así tendencialmente marcada, con algunas ligeras variaciones anuales: en 1808, la yerra parece terminarse en octubre, mientras en 1809 -cuya cantidad de jornadas se encuentra por debajo de los niveles del año anterior- tiende mayormente hacia el fin de la primavera. En 1810, el pico es en octubre, mientras que en 1811 y 1812, a mediados del invierno. Respecto al ciclo agrícola, todas las curvas marcan una baja hacia diciembre que no parece recuperarse en el verano. En efecto, hay menor cantidad de mano de obra contratada. Aquí la estancia comienza a ofrecer mensualidades de 8 a 9 reales en plata contante y sonante.

Sin embargo, hasta aquí no hemos dado cuenta del peso relativo del trabajo asalariado y el trabajo esclavo. Nosotros hemos recalculado el peso relativo para cada año, según nuestras estimaciones de días-hombre:

40 Autor, 2014b, 120-121.

41 Carlos Mayo, Estancia y sociedad, 125. 


\section{Gráfico 2}

Porcentaje de trabajo asalariado y trabajo esclavo según días-hombre, 1808-1812

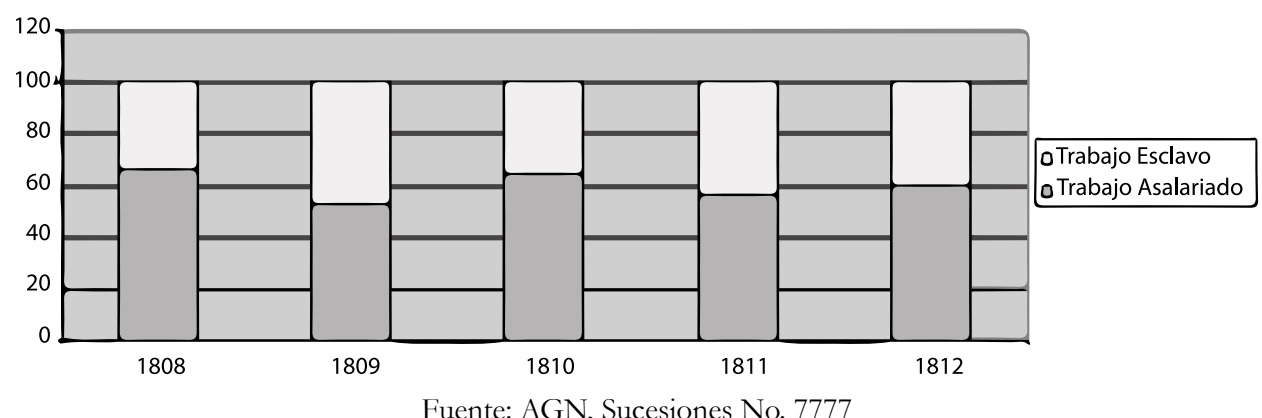

Fuente: AGN, Sucesiones No. 7777

Como ya señalamos, la cuenta graficada aquí no expresa necesariamente la incidencia del trabajo asalariado y del trabajo esclavo, dado que razonaríamos sobre datos que sobreestiman el peso del trabajo esclavo en razón de la producción de valor. Tampoco sabemos -aunque seguramente será difícil discriminarlo- si toda jornada de residencia en la estancia cumplida por parte de los esclavos y peones, constituye una jornada laboral para la producción mercantil de la estancia. Es decir, no sabemos fehacientemente si cumplen tareas "para otro" en términos de producción de excedente. En cambio, los productores directos pueden cumplir -sobre todo los esclavos, con un asentamiento permanente, como el caso ya observado de la familia de Juan- jornadas de trabajo "para sî”. Es decir, jornadas destinadas a su propia reproducción. Nosotros hemos incluso calculado un $60 \%$ de jornadas cubiertas por el trabajo asalariado para los cinco años, contra $40 \%$ cubiertas por el trabajo esclavo, siguiendo el método mencionado en la cita al pie No. 38.

Para poder problematizar estas cifras hasta aquí presentadas, hemos agrupado los meses en dos según lo expresa la Tabla 2: desde marzo a octubre y desde noviembre a febrero. Las cuentas se hicieron respetando los ciclos productivos, es decir, tomando su continuidad. Por ejemplo, en la primera fila partimos de noviembre y diciembre de 1808, sumando enero-febrero de 1809. Además, aquí sí hemos contado los días de 1807 dentro de los primeros casilleros de 1808. 
Tabla 2. Trabajo asalariado y trabajo esclavo según ciclos productivos (1808-1812)

\begin{tabular}{|c|c|c|c|c|c|c|c|c|}
\hline & \multicolumn{4}{|c|}{ Marzo-Octubre } & \multicolumn{3}{c|}{ Noviembre-Febrero } \\
\cline { 2 - 9 } & \multicolumn{2}{|c|}{ T. asalariado } & \multicolumn{2}{c|}{ T. Esclavo } & \multicolumn{2}{c|}{ T. asalariado } & \multicolumn{2}{c|}{ T. Esclavo } \\
\hline Año & $\begin{array}{c}\text { Días-Hom- } \\
\text { bre }\end{array}$ & $\%$ & $\begin{array}{c}\text { Días-Hom- } \\
\text { bre }\end{array}$ & $\%$ & $\begin{array}{c}\text { Días-Hom- } \\
\text { bre }\end{array}$ & $\%$ & $\begin{array}{c}\text { Días-Hom- } \\
\text { bre }\end{array}$ & $\%$ \\
\hline 1808 & 4743 & $71,41 \%$ & 1899 & $28,59 \%$ & 834 & $47,11 \%$ & 936 & $52,89 \%$ \\
\hline 1809 & 2446 & $56,29 \%$ & 1899 & $43,71 \%$ & 769 & $47,82 \%$ & 839 & $52,17 \%$ \\
\hline 1810 & 4225 & $74,10 \%$ & 1477 & $25,90 \%$ & 1601 & $66,00 \%$ & 825 & $34,00 \%$ \\
\hline 1811 & 3080 & $67,70 \%$ & 1470 & $32,30 \%$ & 1609 & $69,00 \%$ & 721 & $31,00 \%$ \\
\hline 1812 & 4216 & $76,70 \%$ & 1281 & $23,30 \%$ & 1141 & $61,28 \%$ & 721 & $38,72 \%$ \\
\hline
\end{tabular}

Fuente: AGN, Sucesiones No. 7777

Si observamos de cerca, podemos apreciar una serie de cuestiones: mientras entre marzo y octubre, cuando explicamos que se desarrollaba el grueso del proceso productivo ganadero (con picos hacia la mitad del invierno y primavera), el trabajo de los peones supera siempre (incluso duplica, salvo en 1809, cuando vimos que se contrató menores jornaleros) al trabajo esclavo. Una versión simplificada del asunto puede observarse en los gráficos siguientes:

\section{Gráfico 3}

Trabajo Asalariado/Trabajo Esclavo entre Marzo y Octubre, 1808-1812

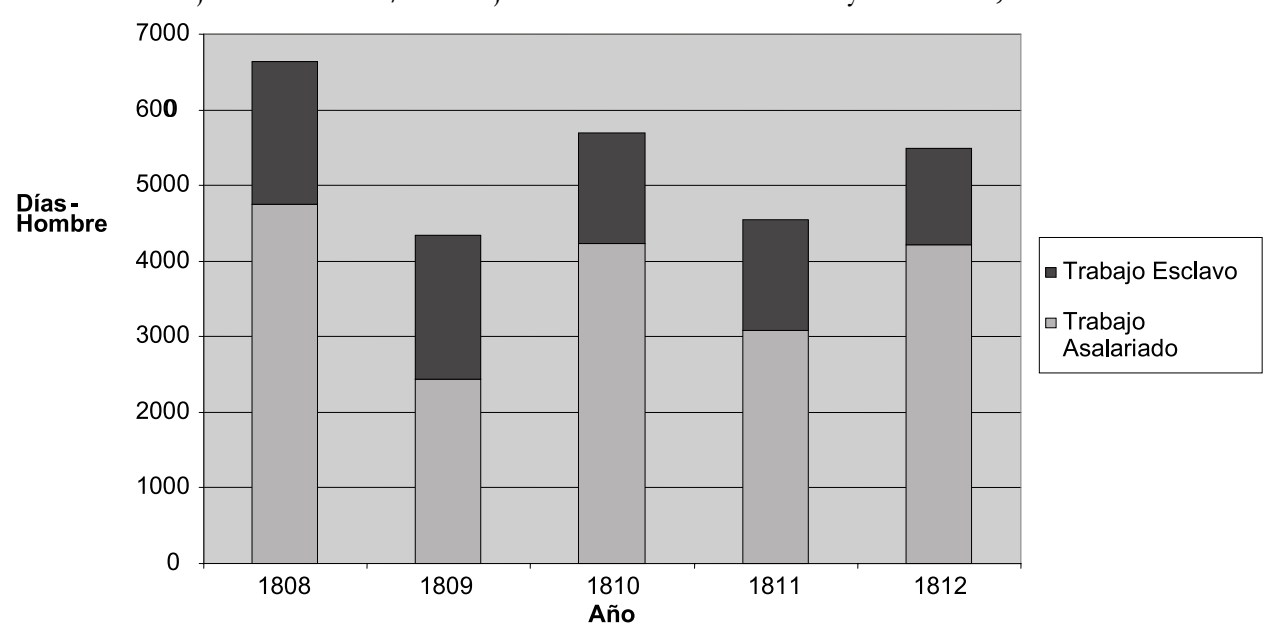

Fuente: AGN, Sucesiones No. 7777 


\section{Gráfico 4.}

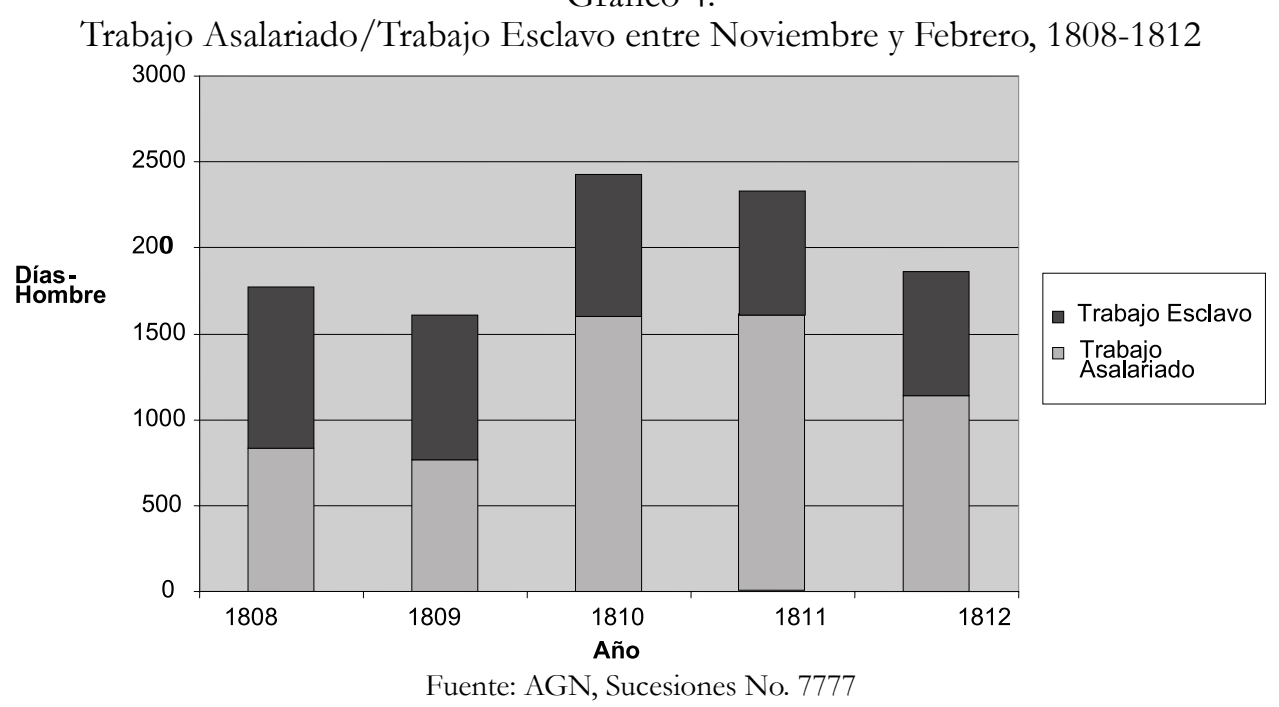

Es decir, con excepción de 1809, en los momentos del año donde se concentraba la producción del valor de la estancia -lo que determina el ciclo ganadero-, el trabajo de los peones superó por encima de la media anual al trabajo esclavo. Dentro de esos períodos del ciclo ganadero, los picos estacionarios (cuando más mano de obra hay en la estancia) son la castración y la yerra.

En cambio, en los períodos que abarcan entre noviembre y febrero, cuando se preparaba y desarrollaba la fase de la siega -que como vimos, no determinaba la reproducción ampliada de la estancia-, el trabajo asalariado tiende a equipararse con el trabajo esclavo (salvo en 1811, cuando el trabajo asalariado se colocó incluso en niveles mayores a los de marzo-octubre del mismo año). Es decir, aunque se requería de una cantidad adecuada de mano de obra (de hecho, es un período estacional), el ciclo agrícola no resultaba determinante para la producción de valor, de modo de repercutir en la ganancia del hacendado. Por ende, la cantidad de fanegas producidas no debía resultar realmente significativa. De lo contrario, es probable que la estancia no haya perdido brazos de modo tan marcado en los últimos 42 meses del año.

En efecto, en términos de jornadas laborales creadoras de la mayor por- 
ción de valor realizado por la estancia, el trabajo asalariado resultó fundamental. Ello tiene efectos para la esclavitud: su importancia se retrae notoriamente. Por supuesto, esto no significa negar el carácter significativo de este último. Sin embargo, el trabajo esclavo tiende a cubrir mayormente las tareas que concentran una menor producción de valor, en comparación con el trabajo asalariado, incluso cuando fueran las estacionarias. Por lo tanto, podemos decir que en la estancia Los Portugueses, el trabajo asalariado se concentraba en torno a la producción de ganado, donde se incorporaba mayor cantidad de valor. Dentro del ciclo ganadero, la castración y la yerra eran los picos estacionarios, donde por unos pocos meses crecía aún más en términos absolutos y relativos la incidencia del trabajo asalariado.

\section{A MANERA DE CONCLUSIÓN: ¿'POR QUÉ LA ESClAVITUd?}

¿Qué función cumple la esclavitud en este tipo de unidades productivas? Como vimos se ha postulado su rentabilidad como mano de obra, la confianza en sus capacidades para establecerse como trabajadores permanentes con funciones directrices, su precio relativamente bajo (amortizable en diez años de trabajo), su ocupación en tareas de todo tipo y no solo permanentes -exceptuando el análisis de Amaral-, en tanto piso mínimo necesario.

La realidad es que hay un aspecto demográfico insoslayable. Una clase de esclavos agrarios constituye un elemento que cubre la demanda de mano de obra en un contexto de escasez demográfica. En una campaña de 15 mil habitantes, la demanda de tareas permanentes y estacionarias del ciclo productivo requiere recurrir a un plantel básico de esclavos que sostenga un piso de trabajadores, a partir del cual se comienzan a contratar peones. No hay que perder de vista que para comienzos del siglo XIX, no ha acontecido una expropiación masiva de la población.

Por el contrario, el proceso de apropiación de la tierra (inculta o en producción, es decir, expropiada) aún no ha culminado. Ello significa que la reproducción de la sociedad no ha generado para estas décadas un proletariado suficiente para la producción de mercancías agrarias por sí mismo. Si bien puede registrarse un crecimiento del volumen de la producción a 
nivel local y mundial, este no se produjo en el mismo ritmo que el crecimiento poblacional. En ese sentido, resulta atendible el argumento que estipula que el acceso a medios de vida por fuera de la relación de peonaje determina la necesidad de un plantel de esclavos. Mucho más, cuando esa población resulta insuficiente.

Ahora bien, desempeñarse de forma eficiente en un rubro productivo como el ganadero en las condiciones materiales en que este se desarrolla -es decir, sin las grandes innovaciones de la última parte del siglo XIXrequiere de un control sobre el ganado en un espacio amplio. Ello requiere entonces de incrementar la escala de esa unidad productiva, lo cual a su vez solo es posible apelando a un número de trabajadores adecuado. Los esclavos constituyen ese piso mínimo indispensable. Incluso cuando una temporada fuera relativamente crítica para la economía productiva de la región (y no han faltado años, como el de 1803), la estancia debía poder consolidar su stock y mantener su escala. En esos años, ese plantel permanente tomaba mayor significación. No obstante, debemos advertir que en el caso de la estancia de Rivero, esos esclavos conformaban un plantel cada vez más reducido: era una de las pocas que podía reubicarlos y delegar cada vez mayor cantidad de tareas en los peones durante todo el año, lo cual se comprueba por el recambio constante de peones. Ello resulta significativo si consideramos que era una estancia de dimensiones inmensas y con uno de los stocks ganaderos más grandes de la campaña. Debemos agregar que el sostenimiento del plantel de esclavos restante comenzaba a ampararse en la reproducción familiar.

Así, el esclavo no producía el grueso del valor. En nuestro estudio de caso, hemos podido observar cómo el trabajo esclavo y el trabajo asalariado se vinculan para la producción de valor, tomando el trabajo asalariado un peso relativo mucho mayor -incluso mayor al que hasta ahora le han asignado- respecto del trabajo esclavo. En efecto, el problema no se agota en el binomio "trabajo permanente/trabajo estacional", ni en el hecho de la preferencia de esclavos para las funciones directrices, sino en el proceso 44 de producción de valor de los ciclos anuales de la estancia. Como hemos visto, la ganadería como tarea productora de valor determina el calendario de la estancia y sus estaciones acentúan los ciclos de contratación de mano 
de obra que marcan sus picos en los meses de la castración y la yerra. Es allí donde el peso del trabajo asalariado se vuelve incluso superior a meses donde se encuentra ya garantizada su predominancia. Sin embargo, a lo largo de todo el ciclo ganadero, la mano de obra asalariada superó al trabajo esclavo. Más allá que los esclavos pudieran realizar los dos tipos de tareas, el grueso del valor es producido por los jornaleros. De este modo, capataces (libres y esclavos), peones y esclavos se combinan para generar la riqueza que sostiene la reproducción ampliada de la estancia.

La esclavitud es así una relación social de producción -y de explotación, como vimos- de carácter precapitalista, que en este contexto de transición histórica al capitalismo, toma una relación subsidiaria respecto de una formación económico-social más amplia ${ }^{42}$. Es decir, las relaciones esclavistas no dominan las relaciones entre los hombres ni en cantidad ni en calidad: allí donde parte de los productores directos eran esclavos, estos no constituían necesariamente fundamentales productores de valor. En dicho sentido, su rol se encuentra claramente detrás de aquella forma de contratación de la mano de obra de peones y jornaleros.

\section{Bibliografía}

\section{Fuentes primarias}

Archivo General de la Nación (AGN), Sucesiones:

AGN, Sucesiones No. 7776.

AGN, Sucesiones No. 7777.

AGN, Sucesiones No. 8143.

AGN, Protocolos Notariales, Registro 6.

AGN, Sala IX, Diezmos.

\section{Fuentes secundarias}

AAVV. "Polémica: gauchos, campesinos y fuerza de trabajo rioplatense colonial". Anuario IHES No. 2 (1987): 25-70.

Amaral, Samuel. Producción y mano de obra rural en Buenos Aires colonial. Buenos Aires: Instituto Di Tella, 1989.

42 Mariano Schlez. Dios, Rey y Monopolio (Buenos Aires: Ediciones RyR, 2009). 
Azcuy Ameghino, Eduardo. El latifundio y la gran propiedad colonial rioplatense. Buenos Aires: García Cambeiro, 1995.

Azcuy Ameghino, Eduardo. La otra Historia. Economía, Estado y Sociedad en el Río de la Plata Colonial. Buenos Aires: Imago Mundi, 2002.

Bagú, Sergio. Estructura social de la Colonia. Buenos Aires: Editorial El Ateneo, 1952.

Barsky, Osvaldo y Julio Djenderedjian. Historia del capitalismo agrario pampeano. La expansión ganadera hasta 1895. Buenos Aires: Universidad de Belgrano/Siglo XXI, 2003.

Brown, Jonathan. "A nineteenth Century Argentine cattle empire". Agricultural History Vol. 1 No. 52 (1978): 160-178.

Cansanello, Orestes Carlos. "Sujeciones personales y puniciones en Buenos Aires durante el siglo XIX". Revista de Historia del Derecho No. 35 (2007): 47-81.

Chayanov, Alexander. La organización de la unidad económica campesina.

Buenos Aires: Ediciones Nueva Visión, 1985 [1925].

Chayanov, Alexander. "Sobre la teoría de los sistemas económicos no capitalistas”. Cuadernos Políticos No. 5 (1975): 15-31.

Crespi, Liliana. "Esclavos, libres y libertos del Río de la Plata. Un lento acceso a la ciudadanía". En La ruta del esclavo en el Río de la Plata. Aportes para el diálogo intercultural, editado por Marisa Pineau. Tres de febrero: EDUNTREF, 2011.

De la Fuente, Alejandro. "La esclavitud, la ley y la reclamación de derechos en Cuba: repensando el debate Tannembaun". Debate y perspectivas. Cuadernos de Historia y Ciencias Sociales 4 (2004): 37-68.

De la Fuente, Alejandro. "Su único derecho: los esclavos y la ley". Debate y perspectivas. Cuadernos de Historia y Ciencias Sociales 4 (2004): 7-22.

De Ste Croix, Geoffrey. La lucha de clases en el mundo griego antiguo: De la época arcaica a la conquista árabe. Barcelona: Editorial Crítica, 1988.

Djenderedjian, Julio, “Optimizando recursos escasos en un área de frontera: La opción por la mano de obra esclava en grandes estancias entrerrianas de tiempos coloniales". Quinto Sol. Vol. 15, No. 2 (2011): 1-27, http://www.scielo.org.ar/scielo.php?script=sci arttext\&pi$\underline{\mathrm{d}=\mathrm{S} 1851-28792011000200001 \& \operatorname{lng}=\mathrm{es} \& \mathrm{nrm}=\mathrm{isO}}$ 
Djenderedjian, Julio. “`Peones o esclavos? Producción rural, tasa de ganancia y alternativas de utilización de la mano de obra en dos grandes estancias del sur del Litoral a fines de la Colonia”. Terceras Jornadas de Historia Económica (2003): 1831-1850.

Fernández Plastino, Alejandro. "Justicia Colonial y esclavos en Buenos Aires virreinal". Anais do X Congreso Internacional de Alada-Universidad Cándido Méndez, Río de Janeiro (2002).

Fernández Ubiña, José. "Esclavitud y explotación en la Antigüedad según Marx". Memorias de historia antigua No. 1 (1977): 47-54.

Flores, Juan Gabriel. “¿Utilidad o producción de valor? Trabajo y relaciones de producción en una estancia colonial rioplatense a partir del caso de Los Portugueses (1802-1809)". Revista Temas Americanistas, No34 (2015): 99-123

Flores, Juan Gabriel. "Hacendados, Cabildo y "corraleros". El acceso de los hacendados al abasto de carne a partir del estudio de dos estancias de la campaña sur de Buenos Aires (1785-1809)". Revista Sociedades Precapitalistas, Vol. 4, No1 (2014)

Garavaglia, Juan Carlos. "Tres estancias del sur bonaerense en un período de 'transición' (1790-1834)". En Problemas de Historia agraria. Nuevos debates y perspectivas de investigación, editado por María Bjerg y Andrea Reguera. Tandil: Instituto de Estudios Histórico Sociales-Facultad de Ciencias Humanas-Universidad Nacional del Centro de la Provincia de Buenos Aires, 1995, 79-123.

Garavaglia, Juan Carlos. Pastores y labradores de Buenos Aires: una historia agraria de la campaña bonaerense, 1700-1830. Buenos Aires: Ediciones de la Flor, 1999.

Gelman, Jorge. "Sobre esclavos, peones, gauchos y campesinos: el trabajo y los trabajadores en una estancia colonial rioplatense". En El mundo rural rioplatense a fines de la época colonial: estudios sobre producción y mano de obra, editado por Juan Carlos Garavaglia y Jorge Gelman. Buenos Aires: Fundación Simón Rodríguez, 1989: 43-83.

Gelman, Jorge. Campesinos y estancieros. Una región del Río de la Plata a fines de la época colonial. Buenos Aires: Ediciones Libros del Riel, 1998. 
Giberti, Horacio. Historia económica de la ganadería argentina. Buenos Aires: Solar Hachette, 1974 [1954].

Goldberg, Marta. "La población negra y mulata de la ciudad de Buenos Aires 1810-1840”. Desarrollo Económico, No. 16, (1976): 79-91.

Goldberg, Marta y Silvia Mallo. "Trabajo y vida cotidiana de los africanos de Buenos Aires (1750-1850)". En Vida cotidiana de los negros en Hispanoamérica, editado por Marta Golberg. Madrid: Ignacio Larramendi-MAPFRE Tavera, 2005.

Grupo de Investigación en Historia Rural Rioplatense. "La sociedad rural bonaerense a principios del siglo XIX. Un análisis a partir de las categorías ocupacionales". En En busca de un tiempo perdido. La economía de Buenos Aires en el país de la abundancia, 1750-1864, editado por Raúl Fradkin y Juan Carlos Garavaglia. Buenos Aires: Prometeo Libros, 2004.

Halperin Donghi, Tulio. "Una estancia en la campaña de Buenos Aires, 1753-1809”. En Haciendas, latifundios y plantaciones en América Latina, editado por Enrique Florescano. México: Siglo XXI, 1975, 447-463.

Halperin Donghi, Tulio. Revolución y guerra. Formación de una elite dirigente en la Argentina criolla. Buenos Aires: Siglo XXI, 1972.

Harari, Fabián. "El barro de la historia". En Los Jacobinos Negros, Ciryl Lionel Robert James. Buenos Aires: Ediciones RyR, 2013

Johnson Lyman. Los talleres de la Revolución. La Buenos Aires plebeya y el mundo del Atlántico, 1776-1810. Buenos Aires: Prometeo Libros, 2013.

Johnson, Lyman. "La manumisión de esclavos en el Buenos Aires colonial: un análisis ampliado”. Desarrollo Económico, No. 17 (1978): 637-646.

Levaggi, Abelardo. "La condición jurídica del esclavo en la época hispana". Revista de Historia del Derecho No. 1 (1973): 83-175.

Lucena Salmoral, Manuel. Leyes para esclavos. El ordenamiento jurídico sobre la condición, tratamiento, defensa y represión de los esclavos en las colonias de la América española. Madrid: Fundación MAPFRE, 2005.

Mallo, Silvia. "La población africana en el Río de la Plata. Delito, adaptación y negociación”. En Vida cotidiana de los negros en Hispa- 
noamérica, editado por Marta Goldberg. Madrid: Ignacio Larramendi-MAPFRE, 2005, 1-12.

Mallo, Silvia. "Población afroamericana: del peculio al matrimonio y la propiedad”. Actas del XII Congreso de Arqueología, La Plata (1999). Marx, Karl. El Capital, Tomo I. México: Fondo de Cultura Económica, 2000.

Marx, Karl. El Capital, Tomo II, Vol. 4. Buenos Aires: Siglo XXI, 2009.

Marx, Karl. Elementos fundamentales para la crítica de la Economía Política (Grundisse), 1857-1858, Tomo II. México: Siglo XXI, 2007.

Mayo, Carlos. Estancia y sociedad en La Pampa, 1740-1820. Buenos Aires: Editorial Biblos, 2004.

Meillassoux, Cláude. Antropología de la esclavitud: el vientre de hierro y dinero. México: Siglo XXI, 1990.

Molinari, Diego Luis. La trata de negros. Datos para su estudio en el Río de la Plata. Buenos Aires: Universidad de Buenos Aires, 1944.

Monsma, Karl. "Esclavos y trabajadores libres en las estancias del siglo XIX. Un estudio comparativo de Río Grande Do Sul y Buenos Aires”. En De la Región a la Nación, relaciones de escala para una historia comparada Brasil-Argentina (S. XIX y XX), editado por Andrea Reguera y Marluza Marques Harres. Tandil. Buenos Aires, 2012, 83-120.

Oddone, Jacinto. La burguesía terrateniente argentina. Buenos Aires: Ediciones Libera, 1975.

Paso, Leonardo. Rivadavia y la línea de Mayo. Buenos Aires: Editorial Fundamentos, 1960.

Peña, Milcíades. Antes de Mayo. Buenos Aires: Ediciones Fichas, 1970.

Petit Muñoz, Eugenio; Edmundo Narancio y José Traibel Nelcis. La condición jurídica, económica y política de los negros durante el coloniaje en la Banda Oriental. Montevideo: Publicaciones oficiales de la Facultad de Derecho y Ciencias Sociales, 1947.

Puigróss, Rodolfo. Los caudillos de la Revolución de Mayo. Buenos Aires: Editorial Contrapunto, 1972 [1942].

Rebagliatti, Lucas, "¿Una esclavitud benigna? La historiografía sobre la naturaleza de la esclavitud rioplatense", Andes, Vol. 25, No.2 (2014), http://www.scielo.org.ar/scielo.php?script=sci arttext\&pi$\mathrm{d}=\mathrm{S} 1668-80902014000200005$. 
Rosal, Miguel Ángel. Africanos y afrodescendientes en el Río de la Plata. Siglos XVIII-XIX. Buenos Aires: Dunken, 2009.

Rufer, Mario. Historias negadas: esclavitud, violencia y relaciones de poder en Córdoba de fines del siglo XVIII. Córdoba: Ferreyra Editor, 2005.

Saguier, Eduardo. "La naturaleza estipendiaria de la esclavitud urbana colonial. El caso de Buenos Aires en el siglo XVIII”. Revista Paraguaya de Sociología, No. 74 (1989): 45-54.

Saguier, Eduardo. "Retribución estipendiaria de la esclavitud urbana colonial". En Genealogía de la Tragedia Argentina, Tomo I, Sección B, 6. http://www.er.saguier.org/obragtatomoII/seccion-B/Cap-6/0Com-07.pdf

Salvatore, Roberto y Jonathan Brown. "Trade and proletarianization in Late Colonial Banda Oriental: Evidence from the Estancia de Las Vacas, 1791-1805'. Hispanic American Historical Review Vol 3 No. 67 (1987): 431-459.

Schlez, Mariano. Dios, Rey y Monopolio. Buenos Aires: Ediciones RyR, 2009.

Studer, Elena. La trata de negros en el Río de la Plata durante el siglo XVIII. Buenos Aires: FFyL, UBA, 1958.

Williams, Eric. Capitalismo y esclavitud. Madrid: Editorial Traficantes de Sueños, 2011.

Para citar este artículo: Harari, Emilio Fabián y Flores, Juan Gabriel. "El peso del trabajo esclavo en el ciclo productivo de la campaña de Buenos 50 Aires tardocolonial. Una estimación a partir de un estudio de caso: Los Portugueses (1808-1812)", Historia Caribe Vol. XIII No. 32 (Enero-Junio 2018): 13-50. DOI: http://dx.doi.org/10.15648/hc.32.2018.2 